\title{
EFFECT THE USE OF STEEL FIBERS (DRAMIX) ON REINFORCED CONCRETE SLAB
}

\author{
Faisal Ananda ${ }^{1 *}$, Oni Febriani ${ }^{1}$, Juli Ardita Pribadi ${ }^{1}, \operatorname{Junaidi}^{1}$, Gunawan $^{1}$ \\ ${ }^{1}$ Department of Civil Engineering, State Polytechnic of Bengkalis, Bengkalis 28711, Indonesia
}

(Received: November 2018 / Revised: February 2019 / Accepted: December 2019)

\begin{abstract}
Currently concrete technology continues to grow and continue to innovate one of them using fibers. Fiber concrete has advantages over non-fiber concrete, among others: strong against the effect of shrinkage, ability to reduce crack as well as fire resistance. In this study, concrete mix design using the procedures listed on SNI 03-2834-2000. The sample used is a cylinder with a height of $30 \mathrm{~cm}$ and a width of $15 \mathrm{~cm}$ in diameter, which is used for compression and tensile testing, while the slab is $400 \mathrm{~cm} \times 100 \mathrm{~cm} \times 15 \mathrm{~cm}$. The fiber used is steel fiber (dramix), with the addition of $2 / 3$ of the thickness of the slabs. The charging is done using a two-point loading. From the result of the research, it is found that the loading of non-fiber slab $(0 \%)$ of the initial crack is the maximum crack that has passed the maximum crack allowed with a crack width of $1.3 \mathrm{~mm}$ with a loading of $1160 \mathrm{~kg}$. The initial crack with the largest load is found on the $1 \%$ fiber mixed slab, with the initial crack also being a maximum crack of $0.5 \mathrm{~mm}$ which also has exceeded the required maximum crack. In the $4 \%$ slab the initial crack of $0.1 \mathrm{~mm}$ is a minimal initial crack with a load greater than the load of a non-fiber $(0 \%)$ slab by load1200 kg. While the maximum load on the maximum crack according to the applicable maximum crack conditions, on the $5 \%$ fiber mixed slab with a crack width of $0.32 \mathrm{~mm}$ by loading $1250 \mathrm{~kg}$.
\end{abstract}

Keywords: Slab; Steel fiber; Width crack

\section{INTRODUCTION}

Concrete is an option of various construction materials as structural material in the construction world. As we know, concrete has considerable compressive strength but has a small tensile strength. Concrete is also brittle. In connection with this concrete weakness, various studies have been conducted to improve the mechanical properties of the concrete. One way to improve the mechanical properties of concrete is to innovate by adding micro reinforcement like fiber. The addition of fiber has an impact on increasing tensile strength and minimizing crack width on reinforced concrete structures (Ananda, Soehardjono, Zacoeb, \& Saroji, 2017). Steel fibers can improve the structural strength to reduce in the heavy steel reinforcement requirement. Freeze thaw resistance of the concrete is improved. Durability of the concrete is improved to reduce in the crack widths (Ananda, Saputra, \& Sukri, 2019). Polypropylene and Nylon fibers are used to improve the impact resistance. Many developments have been made in the fiber reinforced concrete (Jodeiri \& Quitalig, 2012). The addition of steel fibres in concrete increases the first cracking load, ultimate load, stiffness and ductility of the concrete beams (Rai \& Joshi, 2014).

\footnotetext{
*Corresponding author's email: faisalananda@polbeng.ac.id
} 
Based on several studies that have been carried out, it is seen that there are three major factors which contribute to the surface crack width in a reinforced concrete beam:

(1) strain release in the concrete in the vicinity of the crack;

(2) relative slip between concrete and steel; and

(3) distance from the neutral axis.

Therefore, crack development in reinforced concrete elements is a complex process, and there is no universally accepted model for estimating crack width and crack spacing. While there is no agreement on the most appropriate model to predict width and spacing of flexural cracks, there is agreement on the major factors affecting crack width. The most influential factor is the tensile strain in the steel under the action of the service loads. Various technical bodies have recommended tolerable crack widths for different exposure conditions. Some of these recommendations are given in Table 1. according American Concrete Institute Number 224R90. These values refer to the surface flexural crack widths computed by the specific crackwidth formula adopted by that body (Carino, 1995).

Table 1 Tolerable crack widths

\begin{tabular}{lc}
\hline Exposure condition & Tolerable crack width $(\mathrm{mm})$ \\
\hline Dry air or protective membrane & 0.41 \\
Humidity, moist air, soil & 0.30 \\
Deicing chemicals & 0.18 \\
Seawater and seawater spray; wetting and & \\
drying & 0.25 \\
Water retaining structures & 0.1 \\
\hline
\end{tabular}

Road construction is a very important facilities in carrying out activities. there are two methods in road construction, rigid pavement and flexible pavement. These two pavements can usually be combined. The most interesting thing about rigid pavement is the use of concrete material. Where as we know for in the area of the researchers themselves the control of vehicles passing on the road is still lacking, so this makes the road conditions quickly damaged. Damage to the road can be in various forms, one of which is a broken that starts in the concrete tensile area. So to strengthen the tensile area try to use additional fiber, one of which is steel fiber.

\section{LITERATURE STUDY}

Fiber concrete is one of the latest innovations that is very much developed, in addition to products that have been developed to add reinforcement, effective and economical value. Many fibers that have been developed in the construction world are used for mixing into concrete, one of which is fiber from steel material. The research conducted by Patil and Sangle (2017) concrete which was added $1.5 \%$ fiber to the weight of the concrete and $20 \%$ of fly ash (class-C) is added as a replacement of binder to its weight. Based on the experimental results, it can be seen that the load carrying capacity of steel fibre increased by $30-50 \%$ than the plain beam for non-prestressed. And load carrying capacity is increased approximately by $30-90 \%$ than the plain prestressed concrete beam.

The use of steel fibres in a concrete mix was found to increase the crack resistance of the beams. Crack width was not more than $6 \mathrm{~mm}$ and $3 \mathrm{~mm}$ in case of the non-prestressed and prestressed steel fibre reinforced concrete beams respectively. The shape of steel fibers also affects the strength of the concrete itself. The strength of the concrete is known as flexural strength, shear strength, tensile strength, compressive strength, and other strengths. From previous research that has been carried out, The cohesive stress-crack separation behavior obtained from the fracture test indicates that the steel fibers are significantly more effective in 
providing crack control in self compacting concrete (SCC) than in normal concrete (NC) (Sahit et al., 2018). A significantly larger crack closing stress is generated in steel fiber reinforced SCC (SFSCC) even at small crack opening when compared with steel fiber reinforced normal concrete (SFNC). The fracture energy of SFSCC obtained from flexure tests is higher than the fracture energy of SFNC. In the shear response of reinforced concrete, there is a significantly larger increase in the shear capacity of SCC with the addition of fibers when compared with relative increase in NC with the addition of fibers. In both NC and SCC, the shear capacity is determined by the failure of stress transfer across the shear crack.

Shear failure in SCC occurs at a small crack opening, less than $0.1 \mathrm{~mm}$ whereas in NC it occurs at an opening of around $1.0 \mathrm{~mm}$. With the addition of fibers, there is an increase in the load carrying capacity and the load transfer across the primary shear crack is sustained for a larger crack opening in both NC and SCC. The shear stress transfer across the primary shear crack in SFSCC is sustained for a crack opening up to $1 \mathrm{~mm}$. The increase in the crack closing stress provided by steel fibers in SCC matrix contributes to an increase in the shear capacity through better crack control, which results in better shear stress transfer characteristics. The relative increases in the shear capacity of NC and SCC with the addition ofsteel fibers are consistent with the relative increases in the fracture energies.

In addition to the positive impact, the fiber also has a negative impact on the compressed area, if it exceeds the condition of the amount of added fiber into the concrete. This needs balance in carrying out the addition of fiber. Research conducted by Ananda, Gunawan, and Saputra (2017) used the reinforced concrete beams with a size of $15 \mathrm{~cm} \times 25 \mathrm{~cm} \times 180 \mathrm{~cm}$ which placed on a simple pedestal. The test was done gradually in every $108 \mathrm{~kg}$ until the reinforced yield reached. The fiber increased from $0 \%, 1.57 \%, 3.14 \%$ and $4.71 \%$ while the performance rebar ratio increased from $2 \# 10,2 \# 12$, and $2 \# 14$. The result shows that additional $4.71 \%$ of maximum fiber decrease compressive strength and rupture modulus while the tensile strength increased. The additional fiber reached a maximum in $4.71 \%$ and the additional diameter of 10 $\mathrm{mm}, 12 \mathrm{~mm}$, and $14 \mathrm{~mm}$ increased the deflections and crack width. Besides affecting compressive strength, fiber also affects the slump value. As we know the value of slump will affect the worakibility in the field. Besides affecting compressive strength, fiber also affects the slump value and will affect the ease of implementation of work in the field such as research carried out by Nehme, László, and El Mir (2017), who carried out the test mechanical response of the steel fiber reinforced self-compacting concrete (SFR-SCC) panels.

To do so, the rheological and mechanical characteristics of SFR-SCC mixtures were evaluated. Slump flow diameter and V-funnel flow time tests were determined at the fresh stage. The compressive strength, and the maximum deflections were recorded for the SFR-SCC panels, applying three different steel fiber contents. Constant parameters were defined as the following: water to cement ratio $(\mathrm{w} / \mathrm{c}=0.51)$, panel geometry $(500 \times 500 \times 50 \mathrm{~mm})$, and fiber type (DRAMIX RC65/35 BN 35). However, variable parameters were the fiber dosages $(0 \mathrm{~kg} / \mathrm{m} 3$, $30 \mathrm{~kg} / \mathrm{m} 3$ and $60 \mathrm{~kg} / \mathrm{m} 3$ ) and the reinforcement layout (none, $\Phi 5.5 / 70 / 70, \Phi 5.5 / 35 / 35 \mathrm{~mm}$ ). Therefore, an objective evaluation between studied parameters could be fulfilled. The results revealed that the workability of SCC mixtures is reduced by increasing the steel fiber content. However, the load deflection capacity is increased by the addition of the steel fibers.

The use of steel fibers in concrete has no difference in the use of any structure. In accordance with the conditions to be achieved in a structure related to service levels tested by McMahon and Birely (2018), where is the fiber-reinforced concrete (FRC), particularly steel FRC (SFRC), offers the potential to improve the service level performance of structures by controlling the width of cracks and potentially allowing for a reduction in the amount of traditional reinforcing steel. Full-scale tests of hybrid reinforced concrete (continuous reinforcement with SFRC) one- 
way slab strips were conducted to investigate the interaction of rebar with SFRC. Parameters varied were slab depth, amount of reinforcement, and location of reinforcement. Readings from strain gages on the rebar were used to investigate the impact of SFRC on the service stresses. Crack width measurements were made at regular intervals and compared to strain readings. In SFRC slabs, service stress limits were reached at larger demands than in RC slabs. When service stress limits were reached in SFRC slabs, crack widths were much smaller than common crack width limits, suggesting design for crack widths may be an appropriate method for addressing serviceability in SFRC slabs. Applying the results of the tests to sample bridges, it was demonstrated that SFRC can be used to either decrease the amount of steel in a bridge deck to satisfy service performance requirements or to increase the slab span without the need for additional reinforcement.

The problem of fiber concrete is also not only in normal concrete, but it is also good for lightweight concrete such as research conducted Altun and Aktaş (2013). Lightweight concrete, having a lower module of elasticity, has a faster rate of crack development in reinforced concrete members. However, steel fibers are employed as an additive to the concrete in order to increase the energy absorption capacity and to control the crack development. Based on these ideas, steel fibers were added to the lightweight concrete and their effects on the behaviors of concrete and reinforced concrete beams were investigated. For this purpose, lightweight concrete and reinforced concrete beam specimens were produced with the addition of steel fibers in different strengths and ratio. The specimens were tested on four points through loading experiments and their utility for building members was investigated. As a result of the study, it is found that steel fiber addition increased the toughness capacity of prismatic concrete beams and their ductility. It also increased bearing strength and ductility of the reinforced concrete beams. Through this experimental study, the performance of the reinforced concrete beams was increased with the addition of steel fibers. It was also concluded that the decrease in the dead load with steel fiber added lightweight concrete can be considered for reinforced concrete beam designs.

The study of the effects of increased use of dramix was also carried out by Gholamhoseini et al. (2016), who conducted a study on A comprehensive experimental study was conducted on reinforced and steel fibre reinforced concrete (SFRC) continuous composite slabs to quantify crack width resulting from shrinkage and gravity loading. Sixteen full scale slab specimens were cast with different types of interface bond between the concrete slab and steel decking (e.g. greased, unembossed decking or standard decking) and different types and amounts of reinforcement in concrete (e.g. mesh, steel fibre or normal reinforcing bars). Each slab was continuous over the interior support and had a roller support at each end. Concrete shrinkage was measured and serviceability behaviour of slabs was studied over a period of 90 days. It was found that the shrinkage strains at 98 days of drying in plain concrete samples and samples of fibre-reinforced concrete with dosages up to $40 \mathrm{~kg} / \mathrm{m} 3$ were similar. There was no cracking due to the creep and shrinkage-induced strains in the mesh-reinforced or fibre-reinforced composite slabs under their self-weight until 90 days of drying. Subsequently, all the slabs were tested under increasing load until failure. The mid-span deflection and end slip versus applied load were monitored and the crack sizes were obtained for each slab for different levels of applied load. Application of steel fibre in excess of $60 \mathrm{~kg} / \mathrm{m} 3$ increased the slip load by $42 \%$ and improved crack control significantly as the maximum crack width was often reduced by $50 \%$.

The use of fiber in the study of plate structure has also been done by (Fall, Shu, Rempling, Lundgren, \& Zandi, 2014). In the design of two-way reinforced concrete slabs, e.g. using the strip or yield line design method, the possibility of redistributing the load between different loading directions is used. The main aim of the present study was to investigate how fibres affect the structural behaviour such as the possibility for redistribution, crack patterns and load- 
carrying capacity. The investigation was conducted by means of experiments on two-way octagonal slabs, simply supported on four edges, centrically loaded with a point load. The slabs spanned $2.2 \mathrm{~m}$ in both directions and the reinforcement amount was twice as large in one direction as in the other, in order to provoke uneven load distribution. Three slabs of each reinforcement configuration were produced and tested: conventionally reinforced slabs, steel fibre reinforced slabs and a combination of both reinforcement types. The reaction force on each supported edge was measured on five rollers per edge. A moderate fibre content (35 $\mathrm{kg} / \mathrm{m} 3$ ) of double hook-end steel fibres was used. The steel fibres affected the structural behaviour significantly by providing post-cracking ductility and by increasing the ultimate load-carrying capacity by approximately $20 \%$. Most significant, the steel fibres influenced the load redistribution in such a way that more load could be transferred to supports in the weaker direction after cracking. Further, more evenly distributed support reactions were obtained in the slabs containing both reinforcement types compared to the case when only conventional reinforcement was used. The slabs reinforced by steel fibres alone did not experience any bending hardening; however, a considerable post-cracking ductility was observed.

\section{METHODOLOGY}

This research was conducted in Laboratory of Materials Test of Civil Engineering Program of State Polytechnic of Bengkalis, by material properties test and also testing of compressive strength, tensile concrete and flexure test slab using addition of dramix steel fiber. The object of this research is cylindrical concrete with diameter $15 \mathrm{~cm}$ and height $30 \mathrm{~cm}$. The test object was a slab with dimension of $400 \mathrm{~cm} \times 100 \mathrm{~cm} \times 15$ with two-point loading and which on a simple pedestal. Condition of maintain exposed to the sun, with concrete compressive strength planned $\mathrm{f}^{\prime c} 20 \mathrm{Mpa}$. The type of steel fiber used is Dramix Steel Fiber. Dramix Steel Fiber has a length of $60 \mathrm{~mm}$ and a diameter of $0.75 \mathrm{~mm}$. Use of fiber of $1 \%$ to $5 \%$ as an additive to the weight of coarse aggregates, based on industry standards. The following are recommendations of maximum dosage of dramix steel fiber according to standard dramix fiber fabrication.

\begin{tabular}{ccc}
\multicolumn{2}{c}{ Table 2 Maximum dosage of dramix steel } \\
\hline $\begin{array}{c}\text { Maximum agregat } \\
\text { Size }(\mathrm{cm})\end{array}$ & \multicolumn{2}{c}{ DOSAGE $\left(\mathrm{KG} / \mathrm{M}^{3}\right)$} \\
& Pour & Pump \\
\hline 6 & 60 & 45 \\
16 & 50 & 35 \\
32 & 35 & 30 \\
\hline
\end{tabular}

Based on the coarse aggregate sieve analysis performed, the maximal aggregate size obtained is $20 \mathrm{~mm}$, then to determine the variation to be used is to interpolate which refers to the pour method.

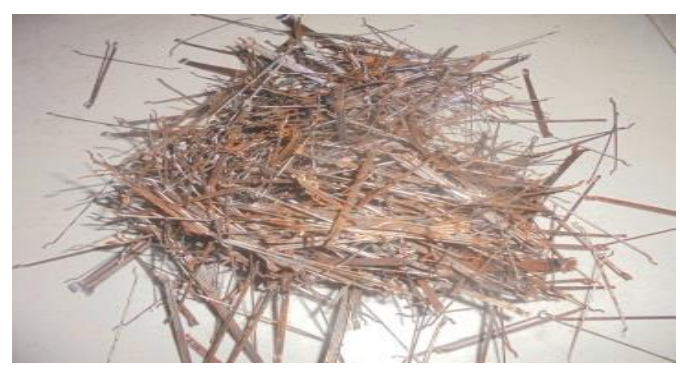

Figure 1 Dramix steel fiber 
The reinforcement used for the slab test object is \#10 $\mathrm{mm}$ with a distance of $20 \mathrm{~cm}$. Maximum load testing with maximum crack width limit of $0.41 \mathrm{~mm}$ according to ACI committe 224R90. Design of concrete mixture using SNI 03-2834-2000 method. The mixing of dramix fibers on the plate is done by adding $2 / 3$ of the thickness of the slab.

\section{RESULTS AND DISCUSSION}

\subsection{Compressive Strength}

From Figure 2 it can be seen that the result of compressive strength with the method of exposure to the sun is increasing and maximally on the concrete with the addition of $3 \%$ fiber, this is more or less the same as the results (Ananda, 2016a). The increase is compared to concrete without additional fiber with a strength of $20.96 \mathrm{MPa}$, which is above the quality of the plan of $20 \mathrm{MPa}$. Maximum increase by $14.21 \%$. From Figure 2, the results of this study find that there is an optimum condition of adding fiber with maximum load, where there is a decrease in strength after the maximum peak load. The decrease in strength can be seen in the addition of fiber after $3 \%$, slowly leading to $4 \%$ fiber. and drastically decreases after fiber is added by $5 \%$.

Table 3 Compressive Strength of Slab

\begin{tabular}{cc}
\hline$\%$ Fiber & Compressive Strength (Mpa) \\
\hline 0 & 20.96 \\
1 & 21.62 \\
2 & 22.05 \\
3 & 23.94 \\
4 & 23.73 \\
5 & 20.02 \\
\hline
\end{tabular}

\section{Compressive Strength of Slab}

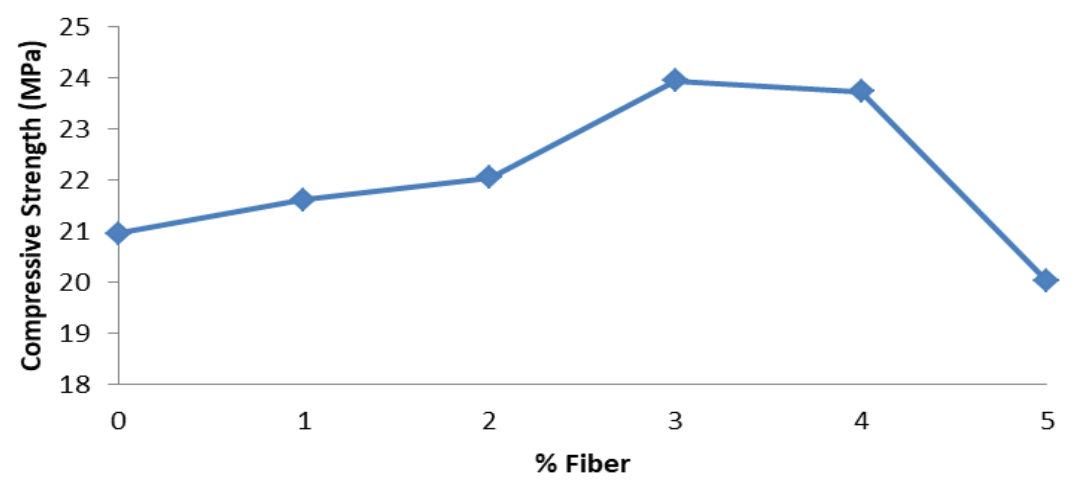

Figure 2 Compressive Strength Of Slab

\subsection{Tensile Strength}

From Figure 3 it can be explained the result of tensile strength with the method of exposure of the sun occurs increase and maximum in the concrete with the addition of $2 \%$ fiber, this value is more or less the same as the previous results ever done (Ananda, 2016b). The increase was compared to concrete without additional fiber with the strength of $2.28 \mathrm{Mpa}$, an increase by $38.15 \%$ with a tensile strength obtained of $3.15 \mathrm{Mpa}$. 
Table 4 Tensile Strength of Slab

\begin{tabular}{cc}
\hline \% Fiber & Tensile strength $(\mathrm{Mpa})$ \\
\hline 0 & 2.28 \\
1 & 2.28 \\
2 & 3.15 \\
3 & 3.11 \\
4 & 2.96 \\
5 & 2.92 \\
\hline
\end{tabular}

From the test of tensile strength, it was seen that the small difference of strength of $2 \%$ fiber addition to the addition of 3\% fiber. As can be seen in Figure 3, in contrast to the results of compressive strength, the tensile strength is indeed the case the peak tensile strength, but the decline was not as extreme as in the results of compressive strength. It can be estimated that the effect on the outcome dramix fiber tensile test work in accordance with previous research (Faisal Ananda et al., 2017).

\section{Tensile Strength of Slab}

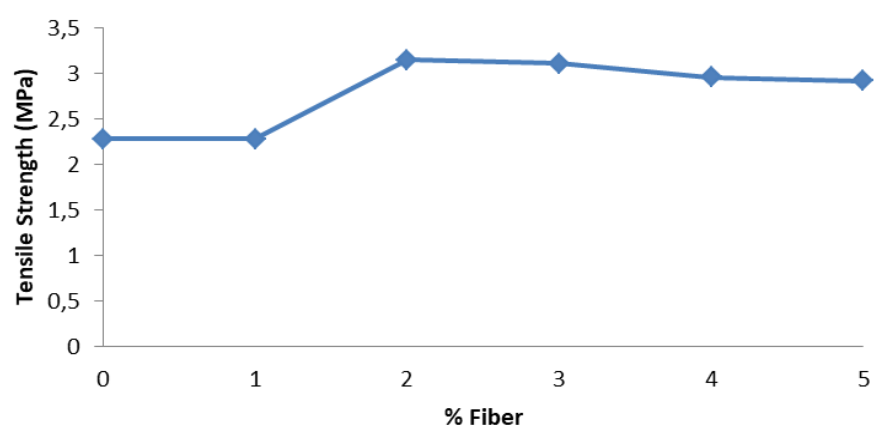

Figure 3 Tensile Strength Of Slab

\subsection{Crack Loads}

The effect of fiber usage can be seen from the loading that occurred in the initial crack and the maximum crack shown in Figures 4. From Figure 4 it can be seen that with the addition of fiber, it can minimize sudden collapse and prevent large crack width. From field observations it was found that concrete without the addition of fibers gives a sudden collapse, where the slab have a large crack width and exceeds the required maximum crack width. Concrete with the addition of fibers is seen to have a good effect on the behavior of concrete cracks, where fiber provides additional strength to the tensile region by minimizing the width of the initial crack of concrete. This is the same as the results of the study from F. Ananda et al. (2017).

The addition of fiber to the concrete can also provide a change of strength, where the tensile strength of the concrete fully retains the positive bending moment resistance in the field area, after the addition of fiber, the tensile strength is divided into fibers. This condition shows a slow decrease in crack width. In addition to the minimization of crack width in both the initial and maximum conditions, also seen the change in testing load. Where with the gradual addition of fibers reaching a maximum (5\%), the load on the initial crack can be expressed as close to the slab without additional fiber, but the crack in the maximal addition of the fibers is smaller. 
Table 5 Effect of loading crack width

\begin{tabular}{ccc}
\hline $\begin{array}{c}\% \\
\text { Fiber }\end{array}$ & Load $(\mathrm{Kg})$ & $\begin{array}{c}\text { Width Crack } \\
(\mathrm{mm})\end{array}$ \\
\hline 0 & 1160 & 1.30 \\
1 & 1400 & 0.50 \\
2 & 920 & 0.57 \\
3 & 1200 & 0.42 \\
4 & 1200 & 0.10 \\
& 1210 & 0.18 \\
& 1220 & 0.22 \\
& 1230 & 0.26 \\
& 1240 & 0.31 \\
5 & 1250 & 0.43 \\
& 1050 & 0.20 \\
& 1100 & 0.24 \\
& 1150 & 0.27 \\
& 1200 & 0.29 \\
& 1250 & 0.32 \\
& 1300 & 0.48 \\
\hline
\end{tabular}

From figure 4 it can also be interpreted that the slab with the addition of fibers gradually reaches a maximum, the slab undergoes a gradual crack from the initial crack until it reaches the maximum crack. Optimal use of fiber for initial cracking of the test implementation was obtained at $4 \%$ fiber, with a load of $1200 \mathrm{~kg}$ and a crack width of $0.1 \mathrm{~mm}$. While at the maximum crack at $5 \%$ fiber with $1250 \mathrm{~kg}$ load, with crack width $0.32 \mathrm{~mm}$.

\section{EFFECT OF LOADING ON CRACK WIDTH}

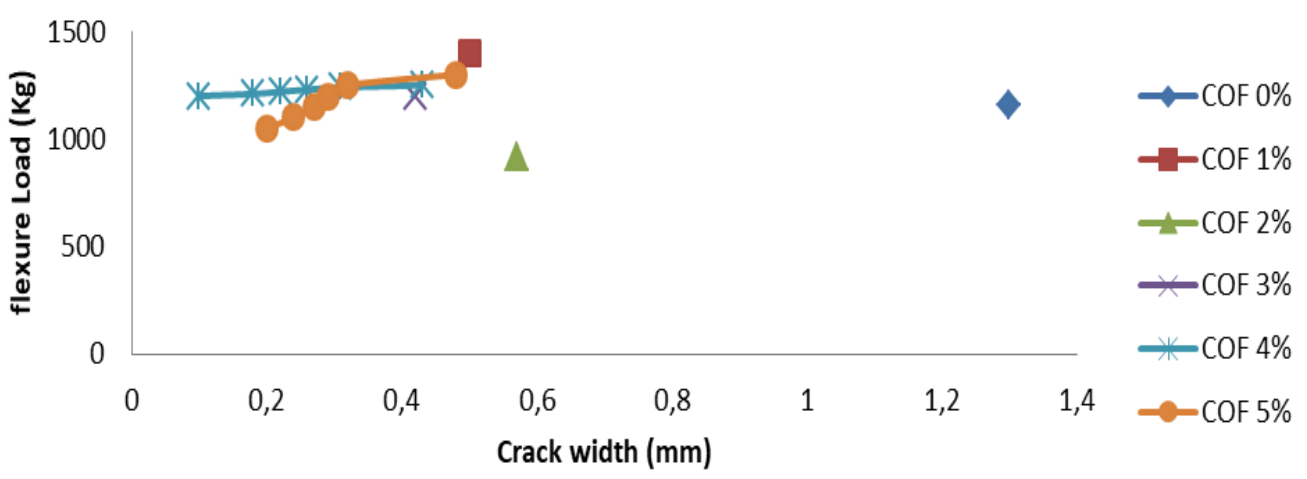

Figure 4 Effect of loading on crack width with addition fiber steel (COF)

\section{CONCLUSION}

Concrete with the addition of steel fiber (dramix) gives effect to the initial and maximum crack width conditions. The fiber effect indicates a slowing of the crack width openings by the gradual addition of load, as occurs in concrete with the addition of $4 \%$ and $5 \%$ fibers. The addition of fiber also has a reverse effect on the attraction that occurs. As is known the tensile strength which was initially supported by concrete as a whole then divided into reinforcing fibers that have been mixed into the concrete. 


\section{REFERENCES}

Altun, F., \& Aktaş, B. (2013). Investigation of reinforced concrete beams behavior of steel fiber added lightweight concrete. Construction and Building Materials, 38, 575-581.

Ananda, F. (2016a). Comparison of the compressive strength value of the treatment process with the use of conventional fibers and dramix fibers. Paper presented at the Seminar Nasional Industri dan teknologi (SNIT), Bengkalis.

Ananda, F. (2016b). Effect of treatment method by adding steel fibers to the compressive strength and tensile strength of concrete. Paper presented at the Seminar Nasional Ketekniksipilan Bidang Vokasional IV, Bali.

Ananda, F., Gunawan, \& Saputra, H. (2017). Effect of adding dramix fiber and treatment on compressive strength, tensile strength and cost of concrete. Paper presented at the Seminar Nasional Teknik Sipil 2.

Ananda, F., Saputra, H., \& Sukri, A. (2019). The influence of bamboo reinforcement and addition of fibers on hollow beams.

Ananda, F., Soehardjono, A., Zacoeb, A., \& Saroji, G. (2017). The reinforced concrete beam deflection and cracking behavior with additional fiber steel.

Carino, N. J. (1995). Prediction of cracking in reinforced concrete structures: US Department of Commerce, National Institute of Standards and Technology.

Fall, D., Shu, J., Rempling, R., Lundgren, K., \& Zandi, K. (2014). Two-way slabs: Experimental investigation of load redistributions in steel fibre reinforced concrete. Engineering Structures, 80, 61-74.

Gholamhoseini, A., Khanlou, A., MacRae, G., Scott, A., Hicks, S., \& Leon, R. (2016). An experimental study on strength and serviceability of reinforced and steel fibre reinforced concrete (SFRC) continuous composite slabs. Engineering Structures, 114, 171-180.

Jodeiri, A. H., \& Quitalig, R. J. (2012). Effect of wirand FS7-II steel wire fibre on flexural capacity of reinforced concrete beam. Journal of Civil Engineering Research, 2(6), 100107.

McMahon, J. A., \& Birely, A. C. (2018). Service performance of steel fiber reinforced concrete (SFRC) slabs. Engineering Structures, 168, 58-68.

Nehme, S. G., László, R., \& El Mir, A. (2017). Mechanical performance of steel fiber reinforced self-compacting concrete in panels. Procedia engineering, 196, 90-96.

Patil, S. P., \& Sangle, K. K. (2017). Shear and flexural behaviour of prestressed and nonprestressed plain and SFRC concrete beams. Journal of King Saud University-Engineering Sciences, 29(4), 321-328.

Rai, A., \& Joshi, Y. (2014). Applications and properties of fibre reinforced concrete. International Journal of Engineering Research and Applications, 4(5), 123-131. 